\title{
Impact of Obesity on Mortality in Adult Trauma Patients
}

Blake Drury ${ }^{1}$, Christopher Kocharians ${ }^{1}$, Fanglong Dong ${ }^{2}$, Louis Tran ${ }^{1}$, Shawhin Beroukhim ${ }^{3}$, Reza Hajjafar $^{1}$, Richard Vara ${ }^{3}$, David Wong ${ }^{3,4}$, Brandon Woodward ${ }^{3,4}$, Michael M. Neeki ${ }^{1,5}$

1. Emergency Medicine, Arrowhead Regional Medical Center, Colton, USA 2. Medicine, Western University of Health Sciences, Pomona, USA 3. Surgery, Arrowhead Regional Medical Center, Colton, USA 4. Surgery, California University of Science and Medicine, San Bernardino, USA 5. Emergency Medicine, California University of Science and Medicine, San Bernardino, USA

Corresponding author: Michael M. Neeki, armcemresearch@gmail.com

\section{Abstract}

\section{Introduction}

Trauma is a major cause of morbidity and mortality amongst all populations in the United States. With the widespread increase of obesity in the United States, studies have been conducted to compare different body mass index (BMI) groups and their clinical outcomes for traumatic injuries. The goal of this study was to retrospectively compare mortality between adult trauma patients with a high BMI to those with a lower BMI as well as investigate whether the mechanism of trauma had an effect on the outcome.

\section{Methods}

This study was a retrospective review of all adult trauma patients presented to the emergency department at Arrowhead Regional Medical Center (ARMC) between January 2014 and October 2019. The outcome was allcause mortality. Patients were grouped according to BMI and mechanisms of injury, including blunt trauma, low velocity penetrating trauma, and high velocity penetrating trauma. Patients were also stratified by injury severity scores (ISS).

\section{Results}

Among the 9642 patients assessed in this study, majority (88\%) of patients sustained blunt trauma. The number of patients among the three different BMI groups was appropriately equal with $34.4 \%$ of normal BMI, 34.6\% overweight, and $31.1 \%$ obese. The overall mortality of all patients studied was $2.6 \%(n=248)$. There was no statistically significant difference in mortality among the three different BMI groups for blunt trauma, penetrating trauma, and subgroup analyses stratified by ISS score (ISS $<16$ or ISS $\geqslant 16$ ).

\section{Conclusion}

Review began 01/29/2021 Review ended 02/09/2021 Published 02/15/2021

\section{(c) Copyright 2021}

Drury et al. This is an open access article distributed under the terms of the Creative Commons Attribution License CC-BY 4.0., which permits unrestricted use, distribution, and reproduction in any medium, provided the original author and source are credited.
Our study found no statistically significant differences in mortality among the three BMI groups in regard to mortality, even when stratified by ISS, or mechanism of injury, and traumatic velocities.

Categories: Emergency Medicine
Keywords: body mass index: bmi, blunt truma, penetrating trauma, mortality

\section{Introduction}

Trauma is a leading cause of death and disability in the United States (US), ranking only behind heart disease and cancer [1]. In 2017, the Centers for Disease Control and Prevention reported that deaths from unintentional injuries was nearly 170,000 [2]. The economic burden of trauma-related injuries is also high. Accounting for both direct healthcare cost and lost productivity, the impact to the US economy has been estimated to be $\$ 671$ billion annually [3].

The rising prevalence of obesity in the US is another major economic burden to the healthcare system. One study estimated that obesity accounts for $21 \%$ of all healthcare-related expenses [4]. Obesity is also a significant comorbidity among patients who suffer traumatic injuries. Obese patients have a $25 \%$ increased risk of workplace injury [5]. When compared to patients of normal weight (body mass index, BMI<18.5 $\mathrm{kg} / \mathrm{m}^{2}$ ), the odds of sustaining an injury were found to be up to $48 \%$ higher in overweight and obese individuals [6].

The effect of obesity in trauma patients has been debated. The obesity paradox is the association of decreased mortality of obese patients in certain conditions. Some have argued that having an increased BMI may confer a protective effect in trauma [7,8]. However, others have contended that an increased BMI makes no difference or may lead to a higher mortality rate [9-11]. This study aimed to examine the difference in 
mortality with different BMI groups among adult trauma patients. Furthermore, this study also investigated if the mechanism and severity of injury would impact the mortality rates among the different BMI groups.

\section{Materials And Methods}

This study was approved by the Institutional Review Board at Arrowhead Regional Medical Center (ARMC). ARMC is a 456-bed acute care teaching facility and American College of Surgeons certified level II trauma center located in San Bernardino County, California. The ARMC emergency department (ED) is one of the busiest in the state of California with more than 100,000 visits and more than 3,000 adult traumas annually. All patients with traumatic injuries were evaluated and managed by qualified providers in accordance with Advanced Trauma Life Support (ATLS) [12].

This was a retrospective chart review of patients who visited ARMC ED between January 2014 and October 2019. Inclusion criteria for this study consisted of adult trauma patients of 18 years and older who sustained penetrating or blunt trauma. Patients were excluded if they were under the age of 18 , did not sustain blunt or penetrating trauma, or did not have a clear recorded BMI in the electronic medical record. The primary objective of this study was to determine the association between mortality at hospital discharge and BMI groups. Data were separated into three BMI groups: normal weight (BMI 18.5-24.9 kg/m²), overweight (BMI $25-29.9 \mathrm{~kg} / \mathrm{m}^{2}$ ), and obese (BMI $30+\mathrm{kg} / \mathrm{m}^{2}$ ). Additional variables assessed in this study included age, sex, injury severity score (ISS), mechanism of injury (blunt vs penetrating), and traumatic velocities (low- vs high-velocity injury). Low-velocity penetrating injuries refer to those items that produce less tissue distraction, and high-velocity penetrating injuries refer to those items that produce wider tissue distraction as a result of high level of kinetic energy, similar to those definitions used by Kuhajda et al. [13].

All statistical analyses were conducted using the SAS software for Windows version 9.4 (Cary, North Carolina, USA). Descriptive statistics were presented as means and standard deviations for continuous variables, along with frequencies and proportions for categorical variables. Chi-square tests were conducted to assess the association between the categorical outcomes and the three BMI categories. All statistical analyses were two-sided. P-value $<0.05$ was considered to be statistically significant.

\section{Results}

A total of 9972 patients were included in the original database. Three patients were excluded for unclear documentation on the mechanisms of injury. An additional 327 patients were excluded for insufficient information regarding their BMI. As a result, a total of 9642 patients were included in the final analysis. Figure 1 presents the detailed patient flow chart.

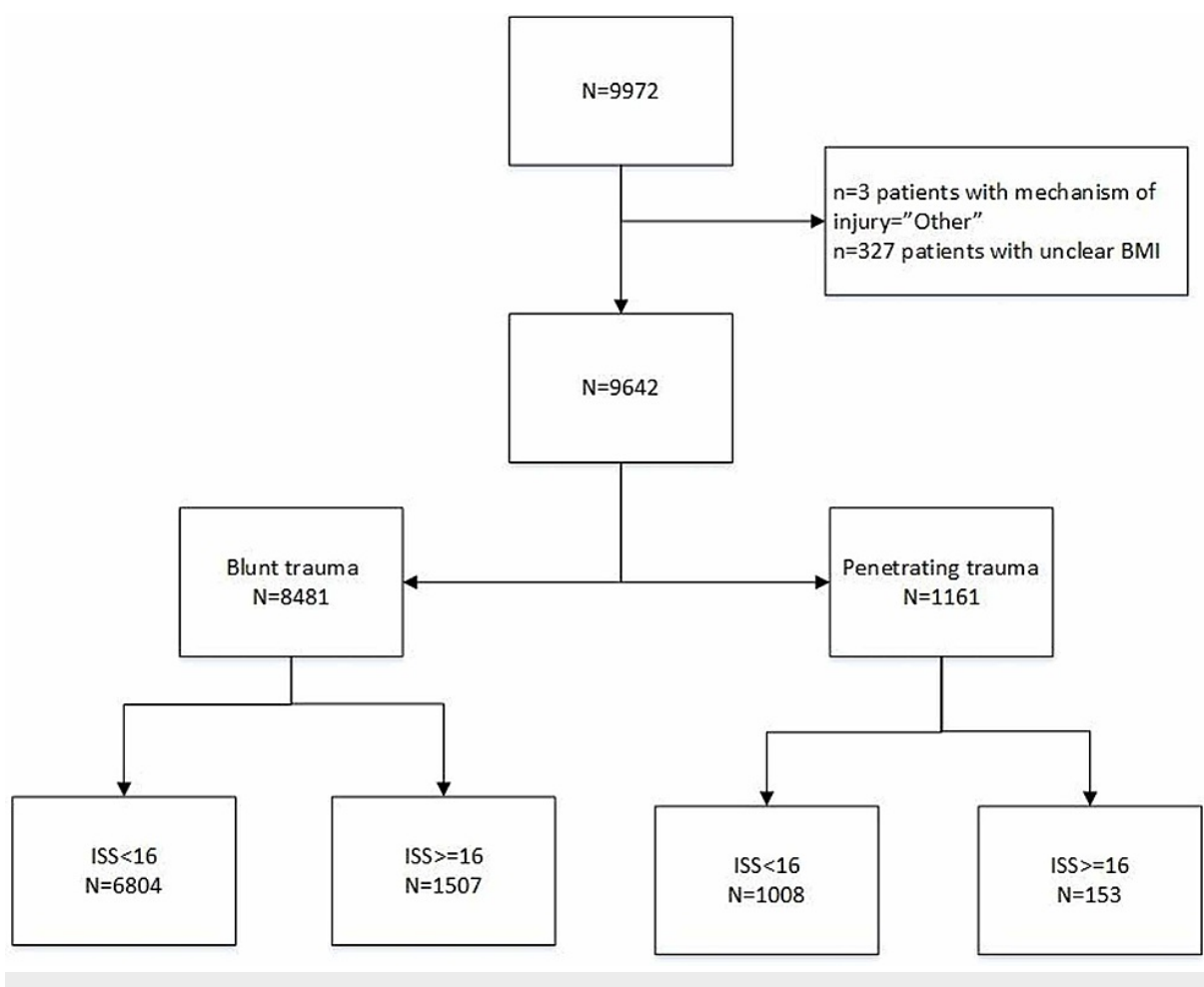

FIGURE 1: Patient flow chart

ISS: injury severity scores; BMI: body mass index. 


\section{Cureus}

Table 1 presents the descriptive summaries for these 9642 patients. The average age was $46.14(\mathrm{SD}=20.4)$ years. The average ISS score was $9.54(\mathrm{SD}=8.2)$. Majority of patients were male $(70.9 \%, \mathrm{n}=6837)$ and sustained blunt trauma $(88.0 \%, \mathrm{n}=8481)$. Proportions of each BMI category were approximately equal, with $34.4 \%$ being normal BMI, $34.6 \%$ being overweight, and $31.1 \%$ being obese. The overall mortality rate was $2.6 \%(n=248)$.

\begin{tabular}{ll}
\hline BMI & $28.31 \pm 6.87$ \\
ISS & $9.54 \pm 8.2$ \\
Age & $46.14 \pm 20.4$ \\
Gender & \\
Female & $2805(29.1 \%)$ \\
Male & $6837(70.9 \%)$ \\
Mechanism of Injury & \\
Blunt & $8481(88 \%)$ \\
Penetrating & $1161(12 \%)$ \\
BMI Group & \\
18.5-24.9 kg/m ${ }^{2}$ & $3314(34.4 \%)$ \\
$25-29.9 \mathrm{~kg} / \mathrm{m}^{2}$ & $3334(34.6 \%)$ \\
$30+\mathrm{kg} / \mathrm{m}^{2}$ & $2994(31.1 \%)$ \\
ISS group & \\
$<16$ & $9394(97.4 \%)$ \\
$\geq 16$ & $248(2.6 \%)$ \\
Missing ISS values & $7812(82.5 \%)$ \\
Discharge Disposition & $1660(17.5 \%)$ \\
Alive & 170 \\
Dead & \\
\hline
\end{tabular}

TABLE 1: Demographic summary of patients

ISS: injury severity scores; BMI: body mass index.

Analyses were conducted to assess the association between BMI and mortality in patients sustaining different mechanisms of injury. Table 2 presents the analysis results. For both blunt and penetrating trauma combined, there was no statistically significant difference in mortality between the three BMI groups $(\mathrm{p}=0.3420)$. There was no statistically significant difference in mortality between the three BMI groups within the ISS $<16$ group $(p=0.2335)$ and within the ISS $\geqslant 16$ group $(p=0.9319)$. 


\begin{tabular}{|c|c|c|c|c|c|}
\hline & & BMI 18.5-24.9 & BMI 25-29.9 & BMI 30+ & p-value \\
\hline \multicolumn{6}{|l|}{ Overall Analysis } \\
\hline \multirow[t]{3}{*}{ Both Blunt and Penetrating combined } & Overall & 96/3314 (2.9\%) & $81 / 3314(2.4 \%)$ & $71 / 3314(2.4 \%)$ & 0.3420 \\
\hline & ISS $<16$ & 29/2660 (1.1\%) & $19 / 2660(0.7 \%)$ & $18 / 2660(0.7 \%)$ & 0.2335 \\
\hline & ISS $\geq 16$ & 65/594 (10.9\%) & 61/594 (10.3\%) & $52 / 594(10.9 \%)$ & 0.9319 \\
\hline \multicolumn{6}{|l|}{ Subgroup Analysis } \\
\hline & Overall & $84 / 2901(2.9 \%)$ & $76 / 2900(2.6 \%)$ & $63 / 2680(2.4 \%)$ & 0.4457 \\
\hline \multirow[t]{2}{*}{ Blunt Trauma } & ISS $<16$ & $28 / 2300(1.2 \%)$ & $18 / 2320(0.8 \%)$ & $15 / 2184(0.7 \%)$ & 0.127 \\
\hline & $I S S \geq 16$ & $54 / 541(10 \%)$ & $57 / 528$ (10.8\%) & $47 / 438$ (10.7\%) & 0.892 \\
\hline Penetrating Trauma & Overall & $12 / 413(2.9 \%)$ & $5 / 434(1.2 \%)$ & $8 / 314(2.6 \%)$ & 0.1821 \\
\hline \multirow{2}{*}{ high velocity } & ISS $<16$ & 0/143 (0\%) & 0/105 (0\%) & 0/103 (0\%) & N/A \\
\hline & ISS $\geq 16$ & $11 / 41(26.8 \%)$ & $4 / 41(9.8 \%)$ & $5 / 35(14.3 \%)$ & 0.1057 \\
\hline \multirow{2}{*}{ low velocity } & ISS $<16$ & $1 / 126(0.8 \%)$ & $1 / 151(0.7 \%)$ & $3 / 102(2.9 \%)$ & 0.3235 \\
\hline & ISS $\geq 16$ & $0 / 10(0 \%)$ & $0 / 14(0 \%)$ & $0 / 2(0 \%)$ & N/A \\
\hline
\end{tabular}

\section{TABLE 2: Overall mortality by mechanism of injury and ISS group}

*All values are presented as number of mortality/number of patients in that strata with the corresponding percentage inside the parenthesis.

ISS: injury severity scores; BMI: body mass index.

Two subgroup analyses were conducted to further assess the association between BMI and mortality. The results were also presented in Table 2 . For blunt trauma overall, there was no statistically significant difference in mortality between the three BMI groups $(\mathrm{p}=0.4457)$. Within each subgroup analysis, there was no statistically significant difference in mortality between the three BMI groups ( $\mathrm{p}=0.127$ for blunt trauma with ISS $<16$ subgroup, $\mathrm{p}=0.892$ for blunt trauma with ISS $\geqslant 16$ ).

For all penetrating traumas, there was no statistically significant difference in mortality between the three BMI groups ( $\mathrm{p}=0.1821$ ). The overweight BMI group had the lowest mortality rate $(1.2 \%)$; whereas, the normal BMI group had the highest mortality rate (2.9\%) overall. For each subgroup analysis, there was no statistically significant difference in mortality between the three BMI groups (all p-values $>0.05$ ).

\section{Discussion}

There has been inconsistent findings regarding the effect of obesity on mortality among trauma patients. One study observed that patients with higher BMI had a lower mortality in injuries from falls, but also had longer hospital length of stay and a decreased likelihood to be discharged home [7]. Another study examined patients with blunt abdominal trauma and found that morbidly obese patients (BMI $\geqslant 40 \mathrm{~kg} / \mathrm{m}^{2}$ ) are less likely to have a gastrointestinal injury or need an operative intervention for hollow viscus injury when compared with underweight patients [14]. Treto et al. reported that mortality after blunt trauma was significantly higher in patients classified as underweight $\left(\mathrm{BMI}<18.5 \mathrm{~kg} / \mathrm{m}^{2}\right)$ when compared to those with normal BMI [15]. Similarly, Bloom and colleagues found that patients with higher BMI are less likely to have severe injuries or need an operation after sustaining an abdominal stab wound. They noted that patients with $\mathrm{BMI}<18.5 \mathrm{~kg} / \mathrm{m}^{2}$ required an operation three times more often than those with BMI $>35 \mathrm{~kg} / \mathrm{m}^{2}$ [8].

Various theories on the protective effect of obesity in trauma have been proposed. One hypothesis is that the extra subcutaneous fat seen in obese patients functions similarly to an airbag, absorbing the forces generated in a collision. Additionally, the extra adipose tissue in obese patients provides a greater distance to the internal organs, which may be protective in penetrating injuries [16]. Patients who are morbidly obese therefore have a mechanical and physical protective barrier for both blunt and penetrating traumas. Our study leans toward supporting this theory. While not statistically significant, the highest mortality rates in our study were found in the groups with the lowest BMI.

In contrast, other investigators came to the opposite conclusion in their research outcomes. Neville and 
colleagues noted a higher incidence of multiple organ failure and mortality rate among obese patients admitted to the intensive care unit following blunt trauma [17]. Additional investigators also reported that obesity is associated with prolonged duration of mechanical ventilation, ICU, and hospital length of stay [18]. Other researchers have suggested that the proinflammatory state, metabolic syndrome, and cardiopulmonary pathologies in obesity may lead to increased complications and mortality following trauma [19]. Obese patients have decreased pulmonary function due to changes in lung volume, compliance, and ventilation/perfusion mismatches [20].

Obesity is also an independent risk factor for cardiovascular disease. It is associated with a higher incidence of insulin resistance and deep vein thrombosis [6,21]. One study of more than 46,000 patients noted that respiratory, thromboembolic, and infectious complications were more common in obese trauma patients. The study concluded that obesity is associated with increased mortality following trauma [9]. In contrast, our retrospective study found no significant difference among various BMI groups with regards to overall mortality due to traumatic injuries. These findings held true when stratified for the mechanism of injury, including blunt vs penetrating injuries. Duane and colleagues reported that mortality rates were not found to be different between obese versus non-obese patients after blunt trauma [22]. Nash et al. reported no statistically significant difference between obese and non-obese patients when comparing operative approach, injury location, and postoperative outcomes for penetrating trauma [16]. While obese patients do have increased infectious morbidity, wound dehiscence, and a prolonged length of stay, increased BMI was not found to be an independent predictor of increased morbidity or mortality after trauma laparotomy [23].

\section{Limitations}

Trauma is a complex and diverse disease with a wide range of presentations. It is nearly impossible to properly compare the severity of sustained injuries in a retrospective study using the ISS. The ISS has been criticized for underestimating the severity of the trauma and can cause statistically significant differences in mortality with the same score generated [24,25]. A severely injured brain is not managed the same way as a severely injured lung, liver, or bowel. Furthermore, the impact of obesity will vary depending on the type and anatomical location of the injury. While the excess adipose tissue may confer some protection for abdominal trauma, it may do nothing for head trauma.

Similarly, obesity is a complex disease and can have diverse physiologic and anatomic complications. Since obesity predisposes patients to many other comorbidities, these may need to be scrutinized individually. Specific areas for investigations may need to take into account the presence of pre-existing conditions as well as the development of complications related to obesity during hospital stay.

\section{Conclusions}

The study found no statistically significant difference in mortality among the three BMI groups, even when stratified by blunt versus penetrating traumas, ISS, and traumatic velocities. Evidence suggests that there is a multifactorial process that occurs amongst obese patients with traumatic injuries. Further prospective studies are needed to clarify and evaluate the specifics of the pathophysiological process after a traumatic event in a different BMI population.

\section{Additional Information \\ Disclosures}

Human subjects: Consent was obtained or waived by all participants in this study. Arrowhead Regional Medical Center IRB issued approval 18-17. Animal subjects: All authors have confirmed that this study did not involve animal subjects or tissue. Conflicts of interest: In compliance with the ICMJE uniform disclosure form, all authors declare the following: Payment/services info: All authors have declared that no financial support was received from any organization for the submitted work. Financial relationships: All authors have declared that they have no financial relationships at present or within the previous three years with any organizations that might have an interest in the submitted work. Other relationships: All authors have declared that there are no other relationships or activities that could appear to have influenced the submitted work.

\section{References}

1. DiMaggio C, Ayoung-Chee P, Shinseki M, et al.: Traumatic injury in the United States: in-patient epidemiology 2000-2011. Injury. 2016, 47:1393-1403. 10.1016/j.injury.2016.04.002

2. Centers for Disease Control and Prevention: accidents or unintentional injuries . (2020). Accessed: October 15, 2020: https://www.cdc.gov/nchs/fastats/accidental-injury.htm.

3. Centers for Disease Control and Prevention: cost of injuries and violences in the United States . (2020). Accessed: October 16, 2020: https://www.cdc.gov/injury/wisqars/overview/cost_of_injury.html.

4. Cawley J, Meyerhoefer C: The medical care costs of obesity: an instrumental variables approach . J Health Econ. 2012, 31:219-230. 10.1016/j.jhealeco.2011.10.003

5. Lin TC, Verma SK, Courtney TK: Does obesity contribute to non-fatal occupational injury? Evidence from the National Longitudinal Survey of Youth. Scand J Work Environ Health. 2013, 39:268-275.

6. Gray S, Dieudonne B: Optimizing care for trauma patients with obesity. Cureus. 2018, 10:e3021. 
7. Osborne Z, Rowitz B, Moore H, Oliphant U, Butler J, Olson M, Aucar J: Obesity in trauma: outcomes and disposition trends. Am J Surg. 2014, 207:387-392. 10.1016/j.amjsurg.2013.10.013

8. Bloom MB, Ley EJ, Liou DZ, Tran T, Chung R, Melo N, Margulies DR: Impact of body mass index on injury in abdominal stab wounds: implications for management. J Surg Res. 2015, 197:162-166. 10.1016/j.jss.2015.03.052

9. Hatchimonji IS, Kaufman EJ, Vasquez CR, Shashaty MG, Martin ND, Holena DN: Obesity is associated with mortality and complications after trauma: a state-wide cohort study. J Surg Res. 2020, 247:14-20. 10.1016/j.jss.2019.10.047

10. Chuang JF, Rau CS, Kuo PJ, Chen YC, Hsu SY, Hsieh HY, Hsieh CH: Traumatic injuries among adult obese patients in southern Taiwan: a cross-sectional study based on a trauma registry system. BMC Public Health. 2016, 16:275. 10.1186/s12889-016-2950-z

11. Flegal KM, Kit BK, Orpana H, Graubard BI: Association of all-cause mortality with overweight and obesity using standard body mass index categories: a systematic review and meta-analysis. JAMA. 2013, 309:71-82. 10.1001/jama.2012.113905

12. Neeki MM, Hendy D, Dong F, et al.: Correlating abdominal pain and intra-abdominal injury in patients with blunt abdominal trauma. Trauma Surg Acute Care Open. 2017, 2:e000109. 10.1136/tsaco-2017-000109

13. Kuhajda I, Zarogoulidis K, Kougioumtzi I, et al.: Penetrating trauma. J Thorac Dis. 2014, 6: S461-S465. 10.3978/j.issn.2072-1439.2014.08.51

14. Fu CY, Bajani F, Butler C, et al.: Morbid obesity's silver lining: an armor for hollow viscus in blunt abdominal trauma. World J Surg. 2019, 43:1007-1013. 10.1007/s00268-018-4872-7

15. Treto K, Safcsak K, Chesire D, Bhullar IS: Analysis of mortality in traumatically injured patients based on body mass index and mechanism reveals highest mortality among the underweight in comparison with the ideal weight patients. Am Surg. 2017, 83:341-347.

16. Nash N, Kimbrough CW, Mackowski M, Benns MV, Smith JW, Harbrecht BG, Bozeman M: Is obesity protective in thoracoabdominal penetrating trauma. Am Surg. 2019, 85:34-38. $10.1177 / 000313481908500117$

17. Neville AL, Brown CV, Weng J, Demetriades D, Velmahos GC: Obesity is an independent risk factor of mortality in severely injured blunt trauma patients. Arch Surg. 2004, 139:983-987. 10.1001/archsurg.139.9.983

18. Schieren M, Böhmer AB, Lefering R, Paffrath T, Wappler F, Defosse J: Impact of body mass index on outcomes after thoracic trauma-a matched-triplet analysis of the TraumaRegister DGU ${ }^{\circledR}$ Injury. 2019, 50:96-100. 10.1016/j.injury.2018.09.051

19. Head GA: Cardiovascular and metabolic consequences of obesity. Front Physiol. 2015, 6:32. 10.3389/fphys.2015.00032

20. Varon J, Marik P: Management of the obese critically ill patient. Crit Care Clin. 2001, 17:187-200. 10.1016/S0749-0704(05)70159-7

21. Hubert HB, Feinleib M, McNamara PM, Castelli WP: Obesity as an independent risk factor for cardiovascular disease: a 26-year follow-up of participants in the Framingham Heart Study. Circulation. 1983, 67:968-977. 10.1161/01.CIR.67.5.968

22. Duane TM, Dechert T, Aboutanos MB, Malhotra AK, Ivatury RR: Obesity and outcomes after blunt trauma. J Trauma. 2006, 61:1218-1221. 10.1097/01.ta.0000241022.43088.e1

23. Livingston DH, Lavery RF, N'Kanza A, Anjaria D, Sifri ZC, Mohr AM, Mosenthal AC: Obesity does not increase morbidity and mortality after laparotomy for trauma. Am Surg. 2013, 79:247-252. 10.1177/000313481307900321

24. de Alencar Domingues C, Coimbra R, Poggetti RS, de Souza Nogueira L, de Sousa RMC: New Trauma and Injury Severity Score (TRISS) adjustments for survival prediction. World J Emerg Surg. 2018, 13:12.

25. Russell R, Halcomb E, Caldwell E, Sugrue MJ: Differences in mortality predictions between injury severity score triplets: a significant flaw. J Trauma. 2004, 56:1321-1324. 10.1097/01.TA.0000062763.21379.D9 